\title{
Practical Teaching Model for Training of Outstanding Engineers Dingguo $\mathrm{Yu}^{1}$, Aihong $\mathrm{Qin}^{1}$ and Chenghang $\mathrm{Yu}^{1}$ \\ ${ }^{1}$ School of New Media, Zhejiang University of Media and Communications, Hangzhou, China
}

\author{
Keywords: Practical teaching; Outstanding engineers; School-enterprise cooperation
}

\begin{abstract}
Practical teaching is an important part of training of application-oriented personnel, and in particular the key to cultivating "outstanding engineers". This paper provides an analysis of problems with practical teaching at an application-oriented university in China. Then it describes the new practical teaching system and school-enterprise cooperation platform established by our university during implementation of the "Outstanding Engineers Education and Training Program". This practical teaching system is relatively well-developed and characterized by a "four-step spiral model" that comprises curriculum experiment, course exercise, comprehensive practical training, and graduation project. The cooperation platform was designed to facilitate cooperation between the university and enterprises at multiple levels and it offers both virtual and concrete means of practical training and. This reform has proven to be effective in enhancing all-round practical abilities of the students.
\end{abstract}

\section{Introduction}

The Ministry of Education of the People's Republic of China initiated the "Outstanding Engineers Education and Training Program" (OEETP) in June, 2010 [1]. The OEETP places great emphasis on fostering students' practical skills and ability to solve practical problems. This program requires relative enterprises to take deep participation in personnel training at schools and requests schools to educate engineering students in accordance with the general standards of the program and specific industrial standards. Moreover, more attention should be paid to fostering students' practical and innovation capabilities [2].

According to the latest definition of engineering given by the Massachusetts Institute of Technology, engineering is a creative discipline that deals with application of scientific principles and experience to meet social demands within physical, economic, manpower, political, legal and cultural limits [3]. Based on engineering science and technology, undergraduate engineering education aims to produce qualified engineers that are good at transforming scientific and technological achievements into productivity and capable of addressing engineering problems. It is characterized by practicality, creativity, comprehensiveness and globality [4]. Application-oriented persons mainly undertake non-academic jobs according to certain theoretical norms. Their mission is to apply knowledge in practice by converting abstract theories into operational concepts or concrete product design [5]. Compared to academic researchers specializing in theoretical research and technicians who are good at hands-on operations, application-oriented personnel should possess not only particular theoretical knowledge and professional qualifications, but also the ability to link theory with practice and apply knowledge in practice. Application-oriented universities and universities account for a major portion of higher education institutions in China. Training of outstanding engineers at the undergraduate level is an important part of the OEETP. Practical teaching forms an important part of training of application-oriented personnel, and in particular the key to cultivating "outstanding engineers". It is therefore important to explore the practical teaching models adopted by application-oriented universities.

\section{Analysis of Problems}

The university studied in this paper is an application-oriented higher education institution offering bachelor's degree. It has an emphasis on arts and humanities but does relatively poorly in engineering and technology. The university pays insufficient attention to the education concept of 
engineering qualifications and its environment and conditions for engineering and technical training are much poorer than those of comprehensive universities or engineering universities. A comparison with the general standards of the OEETP and specific industrial requirements revealed the main problems with the previous practical teaching model the university adopted to prepare students for a career in engineering and technology.

First, the university had little interaction with enterprises in personnel training. The OEETP explicitly requires relative enterprises to take deep participation in personnel training at higher education institutions and formulate their own training plans. Moreover, students are required to go through a year of practical training in enterprises. However, there was a lack of interaction between the university and enterprises in engineering and technical training, let alone deep participation of enterprises in personnel training at the university.

Second, the practical teaching system was undeveloped. The previous teaching system consisted of various hands-on activities such as curriculum experiment, course exercise and professional practice. However, this system was undeveloped overall due to a lack of linkage between these components. Additionally, the means and methods used in practical teaching were too monotonous to stimulate the students' proactivity.

Third, the practical teaching model was unsuitable for use in fostering students' engineering capabilities. Traditional teaching models focus on teaching theoretical knowledge as well as reasoning and proving skills, but overlook cultivation of engineering capabilities and qualifications. Students commonly adopt passive learning methods such as memorizing and recalling knowledge, rather than active methods that are oriented to dealing with practical engineering problems.

\section{The Practical Teaching System with a Four-Step Spiral Model}

Cultivating and enhancing the students' practical abilities is a core element of the OEETP. Practical teaching system and model are the key factors affecting the effectiveness of practical training. In order to improve the students' comprehensive engineering capabilities and allow them to associate certain knowledge points with other relevant ones during practical training, the university needed to make necessary addition and subtraction of knowledge points and interconnect different steps of practical teaching into a sound teaching system. To this end, the university proposed a case- and project-based practical training method and constructed a practical teaching system characterized by a four-step spiral model, which comprises curriculum experiment, course exercise, comprehensive practical training, and graduation project, as shown in Fig. 1.

First step - curriculum experiment. A method to verify professional theoretical knowledge, requires students to acquaint themselves with theoretical fundamentals and helps them accumulate knowledge for subsequent courses. As the first step of this training model, curriculum experiment provides a basis for subsequent practical training as well as a chance for students to demonstrate the theoretical knowledge taught in class through hands-on operations. Therefore, curriculum experiment with proper settings holds an important place in the practical teaching system.

Second step - course exercise. A course exercise is a practical exercise specific to a particular course, which normally lasts one week. To complete a course exercise, students need to be skilled in computer operations, software programming, or other hands-on operations. A course exercise is intended to test if students can associate certain knowledge points with other relevant ones after completion of a course. It helps students lay a firm foundation for subsequent practical training.

Third step - comprehensive practical training, focusing on professional skills. This is a small-to medium-scale practical training project incorporating the core content of several professional courses. This project takes place in the 7th academic term and lasts about 2 months. It is aimed at fostering team spirit among the students and strengthening their ability to address practical problems through comprehensive use of expertise and ultimately their engineering qualifications and practical capabilities.

Fourth step - graduation project. As the last step of practical training of university students, graduation project (thesis) plays an important role in supplying the society with innovative and skilled personnel. This step is carried out in the 7-8th terms and at the university's IT training center, 
research groups of teachers, or off-campus training bases. Its goal is to prepare the students to be qualified and adaptable engineers.

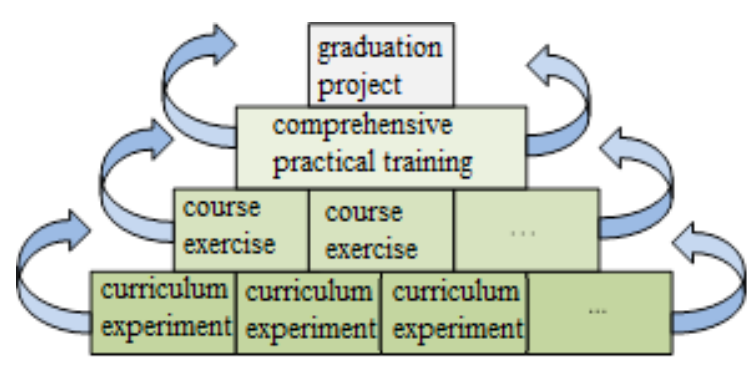

Figure 1. The practical teaching system

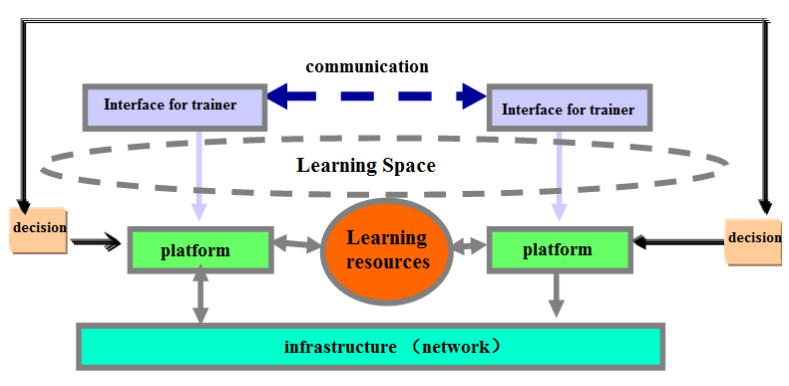

Figure 2. The structure of virtual training platform

\section{The Platform for School-Enterprise Cooperation at Multiple Levels}

The key to successful implementation of the OEETP is for schools to carry out training in cooperation with enterprises and emphasize practical training. Since this program requires enterprises to take deep participation in personnel training at schools and also demand students go through a year of practical training in enterprises, platforms for cooperation between schools and enterprises are necessary. However, application-oriented universities, especially the newly established ones, usually lack such platforms. Another concern is that if schools send all students to enterprises for practical training, the students will certainly be disorganized. This could undermine the effectiveness of practical training and cause management problems.

The university has designed a platform for cooperation with enterprises at multiple levels based on original projects carried out at practical training bases. This platform is constituted of two parts: the online virtual training platform and the concrete school-enterprise cooperation projects. The concrete cooperation projects are oriented to "bringing in" or "sending out". "Bringing in" means bringing in new media companies' experience in engineering projects, operation and management as well as introducing cases of training projects undertaken by famous IT training agencies across the world. These can be realized through lectures on special topics, case teaching, symposiums and other means. Conversely, "sending out" means sending the students to enterprises to take part in concrete engineering projects. Students can receive practical training during the short semesters of the four academic years in addition to the intensive training in the senior year.

The online virtual training platform was a cloud platform for online learning and practical training. It is based on the projects designed by the demonstration center of animation and digital technology experimental teaching in Zhejiang Province and supplemented by materials for use in curriculum experiment, course exercise and graduation project. This platform also incorporates case materials that provide information about training projects undertaken by famous IT training agencies in the world. It offers training videos by which students can independently learn theoretical knowledge as well as the project cases through imitation and practice. This platform is intended to encourage autonomous learning and improve the students' practical capabilities. Fig. 2 shows the structure of this virtual training platform.

\section{Conclusion}

In view of the problems with the traditional model of practical teaching practiced by the university, the university performed exploratory and practical works to find a practical teaching model that is applicable to engineering and technological disciplines in accordance with the requirements of the "Outstanding Engineers Education and Training Program". We have established a sound practical teaching system featuring a "four-step spiral model", as well as a school-enterprise cooperation platform that offers both virtual and concrete means of training. Then the teaching system and the 
cooperation platform were applied in practice with an aim of fostering students' autonomy in learning and improving their practical and innovation capabilities. This reform has produced good results despite the problems exposed during implementation. It has helped strengthen the students' engineering awareness and qualifications and improve their all-round practical skills, and project development and innovation capabilities. These lead to higher quality of employment among the students and higher degrees of satisfaction of their employers.

\section{Acknowledgments}

This work is supported by the Higher Education and Teaching Reform Project of Zhejiang province, China (jg2013119), the Natural Science Foundation of Zhejiang Province, China (LY15F020016), and the Program for Zhejiang Leading Team of Science and Technology Innovation (2011R50019).

\section{References}

[1] Baidu Baike. Outstanding Engineers Education and Training Program [DB], http://baike.baidu.com/, 2015

[2] Lin Jian, On the Professional Training Program of "A Plan for Educating and Training Outstanding Engineers" [J]. TSINGHUA JOURNAL OF EDUCATION, 2011, 32(2):47-55

[3] Zhu Hong, Li Zhiyi, Liu Zhijun. Research and Practice on Higher Engineering Education Reform and Outstanding Engineers Cultivation [J]. Research in Higher Education of Engineering, 2013, 6:68-71

[4] Xu Xiaodong, Bian liang. Exploration and Practice of Research-based Teaching in Undergraduate Engineering Education [J]. Research in Higher Education of Engineering, 2014, 2:43-49

[5] Pan Maoyuan, Shi Huixia. History of Training Practical Talents [J]. JIANGSU HIGHER EDUCATION, 2009, 1:7-10 